\title{
Systematic Review of the Potential of MicroRNAs in Diffuse Large B Cell Lymphoma
}

\author{
Ane Larrabeiti-Etxebarria ${ }^{1,2,{ }^{\dagger}}$, Maria Lopez-Santillan ${ }^{1,3,+}{ }^{\dagger}$, Borja Santos-Zorrozua ${ }^{1}$, \\ Elixabet Lopez-Lopez ${ }^{1,4, *, \ddagger(D)}$ and Africa Garcia-Orad $1,4, \ddagger$ \\ 1 Department of Genetics, Physical Anthropology and Animal Physiology, Faculty of Medicine and Nursing, \\ University of the Basque Country (UPV/EHU), 48940 Leioa, Spain; anelarrabeiti@gmail.com (A.L.-E.); \\ lopezsantillanmaria2@gmail.com (M.L.-S.); Borja.santos@ehu.eus (B.S.-Z.); \\ africa.garciaorad@ehu.eus (A.G.-O.) \\ 2 Pharmacy Service, Araba University Hospital-Txagorritxu, 01009 Vitoria, Spain \\ 3 Medical Oncology Service, Basurto University Hospital, 48013 Bilbao, Spain \\ 4 BioCruces Health Research Institute, 48903 Barakaldo, Spain \\ * Correspondence: Elixabet.lopez@ehu.eus; Tel.: +34-946-01-2951 \\ + These authors contributed equally. \\ $\ddagger$ These authors contributed equally.
}

Received: 28 December 2018; Accepted: 22 January 2019; Published: 26 January 2019

\begin{abstract}
Diffuse large B cell lymphoma (DLBCL) is the most common subtype of invasive non-Hodgkin's lymphoma (NHL). DLBCL presents with variable backgrounds, which results in heterogeneous outcomes among patients. Although new tools have been developed for the classification and management of patients, $40 \%$ of them still have primary refractory disease or relapse. In addition, multiple factors regarding the pathogenesis of this disease remain unclear and identification of novel biomarkers is needed. In this context, recent investigations point to microRNAs as useful biomarkers in cancer. The aim of this systematic review was to provide new insight into the role of miRNAs in the diagnosis, classification, treatment response and prognosis of DLBCL patients. We used the following terms in PubMed" (('Non-coding RNA') OR ('microRNA' OR 'miRNA' OR 'miR') OR ('exosome') OR ('extracellular vesicle') OR ('secretome')) AND ('Diffuse large B cell lymphoma' OR 'DLBCL')" to search for studies evaluating miRNAs as a diagnosis, subtype, treatment response or prognosis biomarkers in primary DLBCL in human patient populations. As a result, the analysis was restricted to the role of miRNAs in tumor tissue and we did not consider circulating miRNAs. A total of thirty-six studies met the inclusion criteria. Among them, twenty-one were classified in the diagnosis category, twenty in classification, five in treatment response and nineteen in prognosis. In this review, we have identified miR-155-5p and miR-21-5p as miRNAs of potential utility for diagnosis, while miR-155-5p and miR-221-3p could be useful for classification. Further studies are needed to exploit the potential of this field.
\end{abstract}

Keywords: lymphoma; microRNA; diagnosis; classification; treatment response; prognosis

\section{Introduction}

Diffuse large B-cell lymphoma (DLBCL) is the most common lymphoid malignancy in adults, accounting for $30-40 \%$ of all non-Hodgkin lymphoma cases [1]. DLBCL presents a very diverse clinical and genetic background, which leads to highly heterogeneous outcomes among patients [2].

The first line therapy for this aggressive malignancy consists of combined chemotherapy including rituximab, prednisone, doxorubicin, vincristine and cyclophosphamide (R-CHOP). Around $75-80 \%$ of patients achieve complete remission with R-CHOP therapy. Nevertheless, approximately up to $40 \%$ of 
patients have primary refractory disease or relapse [3]. Worryingly, those patients tend to respond poorly to additional chemotherapy lines, which remains a major cause of morbidity and mortality [4].

In order to identify DLBCL patients with a higher risk of a poor response to therapy, different tools have been developed. The International Prognostic Index (IPI) predicts overall and progression free survival based on five risk factors: age, tumor stage, serum lactate dehydrogenase (LDH) concentration, performance status and number of extra nodal disease sites [5]. Using those factors, the IPI distinguishes four risk groups with different 5-year overall survival, ranging from 26 to $73 \%$ [6]. Nevertheless, some patients present an unfavorable course of disease despite having a good prognostic index. Another profiling tool uses gene expression profiling (GEP) or immunohistochemical analysis to define two molecular subtypes with different clinical outcomes independent of IPI stratification: the germinal center B-cell-like (GCB) DLBCL, and the activated B-cell-like (ABC) DLBCL. The 5-year survival rates are $60 \%$ for $\mathrm{GCB}$ and $40 \%$ for $\mathrm{ABC}$ subtype $[7,8]$. However, it is not possible to identify all the patients that will not respond to therapy with these profiling tools. Therefore, new biomarkers are needed for a better patient stratification.

In this sense, important knowledge is emerging regarding novel molecular and biological candidates with diagnostic, predictive and prognostic potential in DLBCL, including microRNAs (miRNAs) [9]. MiRNAs are small, non-coding RNAs with a role in gene expression regulation at the post-transcriptional level. They bind the $3^{\prime}$ untranslated region (UTR) of a target mRNA, which leads to their repression or degradation [10]. Through this mechanism, miRNAs regulate more than $50 \%$ of known human genes [11], including genes of the 10 main routes involved in cancer [12].

Accordingly, recent research has shown the potential role of miRNAs as diagnostic, classification and prognostic predictors in cancer [13]. For instance, miR-21 has been intensively studied as a diagnosis tool, being found upregulated in many types of cancer including non-small cell lung cancer (NSCLC) [14]. Other examples include miR-10b, which has been described as a useful tool for the classification of papillary renal cell carcinoma type 2 [15], and miR-183, high expression levels of which have been associated with poor prognosis in different cancer types such as colorectal cancer, pancreatic cancer, lung cancer, gastric cancer, and breast cancer [16].

Abnormal expression of miRNAs is also common in B cell neoplasms, including B cell lymphoma. However, there is inconsistency in the data reported. Consequently, the aim of this systematic review was to clarify the role of deregulated miRNAs in DLBCL tumor samples as more systematically-defined diagnostic, subtype, prediction of treatment response and prognostic biomarkers.

\section{Results}

The detailed search results are included in Figure 1. In brief, the search strategy provided a total of 508 records in the PubMed database. Once the duplicated articles were removed, 338 remained. Of these 338, 239 were excluded after reading the abstract because they did not meet the inclusion criteria. Then, the full texts of the remaining 99 studies, which focused on miRNAs in DLBCL, were read carefully. Additionally, another 63 articles were excluded because there were other coexisting pathologies, miRNAs were not analyzed in the tumor sample, DLBCL was not primarily considered, they did not assess the role of miRNAs in diagnosis, subtype, prediction of treatment response or prognosis, or miRNA expression changes were not considered. A total of 36 studies investigating the role of miRNA expression changes as biomarkers in DLBCL tumor samples were included. Twenty-one of them considered miRNAs as putative DLBCL diagnosis biomarkers, twenty in subtype classification, five in treatment response and nineteen of the studies searched for markers for their role in prognosis. 


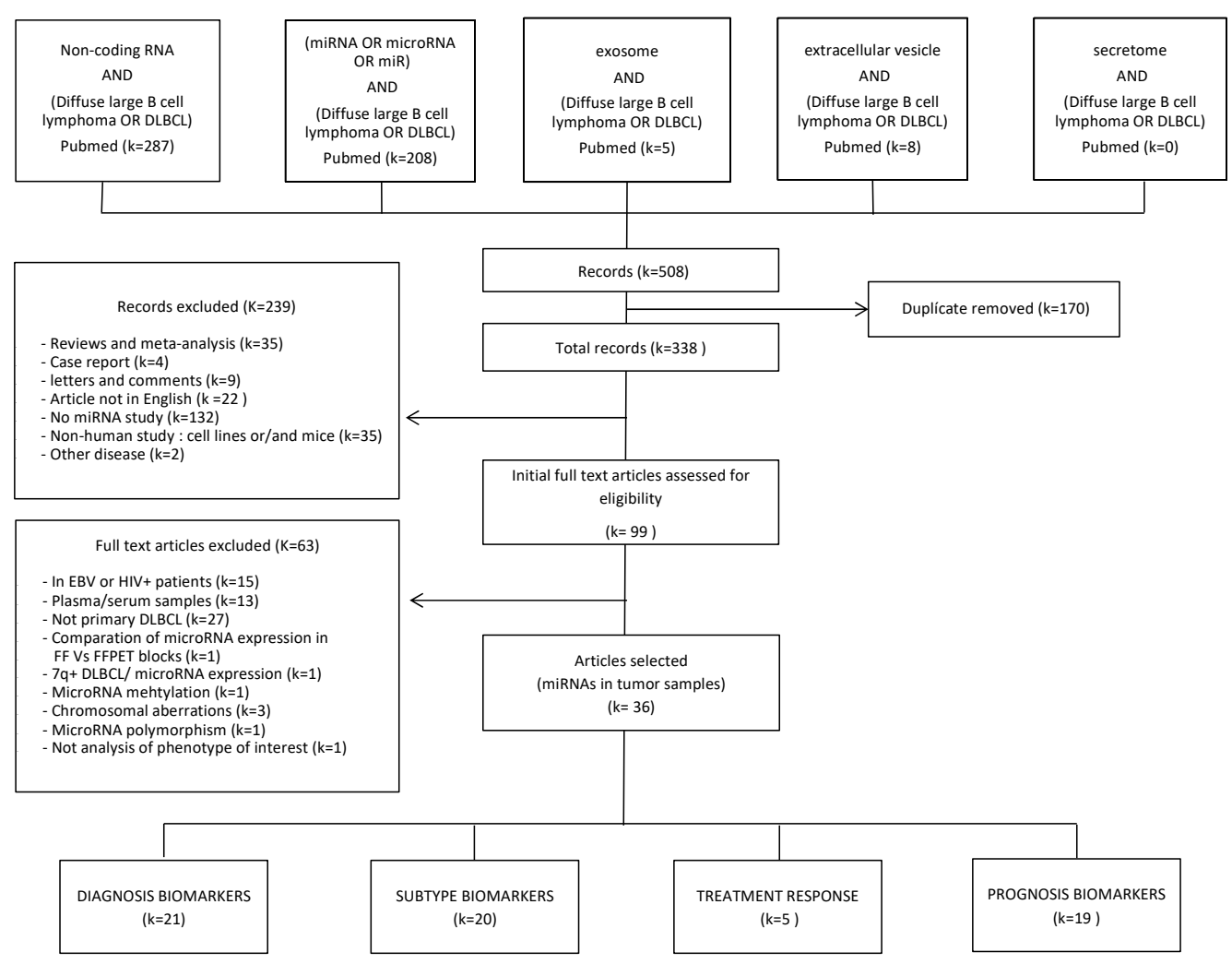

Figure 1. Flow-chart diagram of study selection. $\mathrm{k}=$ number of records.

\subsection{Tumor Tissue miRNAs as Biomarkers for Diagnosis in DLBCL}

Twenty-one studies analyzed the expression of miRNAs by comparing DLBCL cases vs healthy controls [17-37]. These 21 studies provided a total of 140 differentially expressed microRNAs in DLBCL patients compared with healthy control individuals as shown in Table S1.

Regarding the miRNAs that were concordantly deregulated in more than two studies, we identified two miRNAs that were repeatedly reported to be up-regulated in DLBCL patients (miR-155-5p [17,22,24,26,28,30,32-34], miR-21-5p [19,22,26,28,33,36], although some studies did not find a significant association (miR-155-5p [27,29], miR-21-5p [27,32]). We also identified two miRNAs with contradictory results. On the one hand, miR-150-5p was found to be down-regulated in DLBCL patients in four studies $[18,28,31,32]$ and contradictorily up-regulated in DLBCL patients in another study [29], while no significant association was reported in the remaining study [27]. On the other hand, miR-146a/b-5p was found upregulated in three studies $[22,27,30]$ while it was shown to be discordantly downregulated in another study [21], and not significantly associated with DLBCL in two studies [27,28] (Table 1).

\subsection{Tumor Tissue miRNAs as Biomarkers for DLBCL Subtype Classification}

Twenty studies analyzed the role of tumor tissue miRNAs to distinguish between GCB and ABC DLBCL subtypes and their characteristics are provided in Table S2 [19,21,23-28,30,32-34,38-45]. These studies found 93 miRNAs differentially expressed between GCB and ABC DLBCL samples. Among these 93 differentially expressed miRNAs, five miRNAs were concordantly reported in more than two studies. Four of them were reported as down-regulated (miR-155-5p [26-28,30,33,34,38,41,44], miR-221-3p [27,33,41,45], miR-222-3p [27,41,45], and miR-146a/b-5p [28,30,41]) or unchanged (miR-221-3p [28,43], miR-222-3p [28,32,38,43] and miR-146a/b-5p [21,27,28,38,43]) in GCB samples, whereas miR-28-5p was found to be up-regulated $[28,41]$ or unchanged $[28,41]$ in the same subtype (Table 2). 


\subsection{Tumor Tissue miRNAs as Biomarkers for Prediction of Treatment Response in DLBCL}

Five studies were focused in the role of miRNAs in DLBCL tissue as predictive biomarkers of response to R-CHOP treatment $[18,23,24,30,42]$. The characteristics of each study are shown in Table S3. A total of five miRNAs were differentially expressed between good and poor responders. Three microRNAs were found to be associated with a favorable response to therapy (miR-27-3p [18], miR-34a-5p [24] and miR-224-5p [23]), whereas miR-155-5p [30] and miR-146-5p [30] were found to be associated with chemoresistance. However, each miRNA was analyzed in only one study, without any of the results being replicated.

\subsection{Tumor Tissue miRNAs as Biomarkers for DLBCL Prognosis}

The relevance of tumor tissue miRNAs for prognosis in DLBCL patients was analyzed in nineteen studies [18,20,21,23,25-27,30,32,33,37,38,41,42,45-49]. A total of 50 miRNAs with significant reported associations with patient survival were found (Table S4).

Considering the miRNAs with concordant significant results in more than two studies, miR-222-3p, and miR-155-5p were identified. Up-regulation of miR-222-3p [45,48,49] and miR-155-5p [30,38,46] was associated with a worse outcome in three different studies in each case. However, four and eight studies, respectively, did not find any association with prognosis for miR-222-3p [27,32,41,47] and miR-155-5p [26,27,32,33,41,47-49] (Table 3).

\subsection{Pathway Enrichment Analysis}

Predicted target genes for the miRNA that presented the highest evidence of being involved in DLBCL diagnosis (miR-155-5p and miR-21-5p) and in subtype classification (miR-155-5p, miR-221-3p) were identified in silico. Using these lists of genes, we searched for over-represented pathways that could be linked to DLBCL.

MAPK signaling pathway-Homo sapiens (KEGG) was significantly enriched among the predicted target genes of the two miRNAs associated with DLBCL diagnosis (Table S5). Regarding the targets of the two miRNAs associated with DLBCL subtype, signaling by receptors tyrosine kinases (Reactome) was significantly enriched (Table S6). The predicted target genes covered more than $20 \%$ of the genes included in these two pathways (Table 4). 
Table 1. miRNAs significantly associated with DLBCL diagnosis in more than two studies.

\begin{tabular}{|c|c|c|c|c|c|c|c|}
\hline Significant miRNAs & Result & $n$ DLBCL & $n$ Control & Sample Source & Method & n miRNAs & Reference \\
\hline \multirow{11}{*}{$\operatorname{miR}-155-5 p$} & \multirow{9}{*}{ up } & 29 & 32 (RLH) & Tissue & qRT-PCR & 1 & Li et al. 2017 [17] \\
\hline & & 22 & $6(\mathrm{NLN})$ & Biopsie & qRT-PCR & 1 & Huskova et al. 2015 [24] \\
\hline & & 200 & $11(\mathrm{NT})$ & FFPE & qRT-PCR & 3 & Go et al. 2015 [26] \\
\hline & & 45 (DC);75 (VC) & 10 (DC);6 (VC) (NLN) & FF and FFPE & qRT-PCR/array & 177 & Caramuta et al. 2013 [28] \\
\hline & & 90 & 31 (RLN) & FFPE & qRT-PCR & 2 & Zhong et al. 2012 [30] \\
\hline & & 58 & $7(\mathrm{NLN})$ & FFPE & qRT-PCR & 157 & Roehle et al. 2008 [32] \\
\hline & & 48 & 6 (NBC) & FF and FFPE & qRT-PCR & 3 & Lawrie et al. 2007 [33] \\
\hline & & 23 & 2 & FF & Semi RT-PCR & 1 & Eis et al. 2005 [34] \\
\hline & & 24 & 14 (NLN) & FFPE & array & 3100 probes & Tamaddon et al. 2016 [22] \\
\hline & \multirow{2}{*}{ NS } & 92 & 15 & FF & sequencing & miRNAome & Lim 2015 et al. [27] \\
\hline & & 12 & 7 & FFPE & qRT-PCR & 4 & Handal et al. 2013 [29] \\
\hline \multirow{14}{*}{$\operatorname{miR}-21-5 p$} & \multirow{6}{*}{ up } & 55 & 20 (NLN) & FF and FFPE & qRT-PCR & 1 & Liu et al. 2017 [19] \\
\hline & & 26 & 10 (NLN) & FFPE & qRT-PCR & 1 & Song et al. 2017 [36] \\
\hline & & 200 & $11(\mathrm{NT})$ & FFPE & qRT-PCR & 3 & Go et al. 2015 [26] \\
\hline & & 45 (DC);75 (VC) & $10(\mathrm{DC}) ; 6(\mathrm{VC})(\mathrm{NLN})$ & FF and FFPE & qRT-PCR/array & 177 & Caramuta et al. 2013 [28] \\
\hline & & 48 & $6(\mathrm{NBC})$ & FF and FFPE & qRT-PCR & 3 & Lawrie et al. 2007 [33] \\
\hline & & 24 & 14 (NLN) & FFPE & array & 3100 probes & Tamaddon et al. 2016 [22] \\
\hline & \multirow{2}{*}{ NS } & 92 & 15 & FF & sequencing & miRNAome & Lim et al. 2015 [27] \\
\hline & & 58 & 7 (NLN) & FFPE & qRT-PCR & 157 & Roehle et al. 2008 [32] \\
\hline & up & 12 & 7 & FFPE & qRT-PCR & 4 & Handal et al. 2013 [29] \\
\hline & & 45 (DC);75 (VC) & 10 (DC);6 (VC)(NLN) & FF and FFPE & qRT-PCR/array & 177 & Caramuta et al. 2013 [28] \\
\hline & & 36 & $5(\mathrm{NLN})$ & Tissue & qRT-PCR & 8 & Fassina et al. 2012 [31] \\
\hline & down & 58 & 7 (NLN) & FFPE & qRT-PCR & 157 & Roehle et al. 2008 [32] \\
\hline & & 5 & 4 (RLH) & Tissue & nanostring & 800 & Jia et al. 2017 [18] \\
\hline & NS & 92 & 15 & FF & sequencing & miRNAome & Lim et al. 2015 [27] \\
\hline \multirow{4}{*}{$\operatorname{miR}-146 b-5 p$} & down & 106 & 30 (RLH) & FFPE & qRT-PCR & 939 & Wu et al. 2014 [21] \\
\hline & NS & $45(\mathrm{DC}) ; 75(\mathrm{VC})$ & $10(\mathrm{DC}) ; 6(\mathrm{VC})(\mathrm{NLN})$ & FF and FFPE & qRT-PCR/array & 177 & Caramuta et al. 2013 [28] \\
\hline & \multirow{4}{*}{ up } & 92 & 15 & FF & sequencing & miRNAome & Lim et al. 2015 [27] \\
\hline & & 24 & $14(\mathrm{NLN})$ & FFPE & array & 3100 probes & Tamaddon et al. 2016 [22] \\
\hline \multirow{4}{*}{ miR-146a-5p } & & 90 & 31 (RLN) & FFPE & qRT-PCR & 2 & Zhong et al. 2012 [30] \\
\hline & & 24 & 14 (NLN) & FFPE & array & 3100 probes & Tamaddon et al. 2016 [22] \\
\hline & \multirow{2}{*}{ NS } & 45 (DC);75 (VC) & $10(\mathrm{DC}) ; 6(\mathrm{VC})(\mathrm{NLN})$ & FF and FFPE & qRT-PCR/array & 177 & Caramuta et al. 2013 [28] \\
\hline & & 92 & 15 & FF & sequencing & miRNAome & Lim et al. 2015 [27] \\
\hline
\end{tabular}

RLH: Reactive lymphoid hyperplasia; NLN: normal lymph node tissues; NT: normal tonsil; FF: fresh frozen; FFPE: formalin-fixed paraffin-embedded; DC: discovery cohort; VC: validation downregulated in DLBCL patients. 
Table 2. miRNAs significantly associated with DLBCL subtype in more than two studies.

\begin{tabular}{|c|c|c|c|c|c|c|c|}
\hline Significant miRNAs & Result & $n$ GCB & $n \mathrm{ABC}$ & Sample Source & Method & n miRNAs & Reference \\
\hline \multirow{10}{*}{ miR-155-5p } & \multirow{9}{*}{ Down GCB } & 53 & 95 & FFPE & qRT-PCR & 8 & Go et al. 2015 [26] \\
\hline & & 32 & 27 & FFPE & qRT-PCR/array & 377 & Iqbal et al. 2015 [38] \\
\hline & & 20 & 34 & FF and FFPE & qRT-PCR/array & 177 & Caramuta et al. 2013 [28] \\
\hline & & 36 & 31 & FF & qRT-PCR & 1 & Huang et al. 2012 [44] \\
\hline & & 21 & 69 & FFPE & qRT-PCR & 2 & Zhong et al. 2012 [30] \\
\hline & & 32 & 28 & FFPE & Array & 464 & Lawrie et al. 2009 [41] \\
\hline & & 16 & 18 & FF and FFPE & qRT-PCR & 3 & Lawrie et al. 2007 [33] \\
\hline & & 4 & 19 & $\mathrm{FF}$ & Semiq. RT-PCR & 1 & Eis et al. 2005 [34] \\
\hline & & 41 & 30 & $\mathrm{FF}$ & sequencing & miRNAome & Lim et al. 2015 [27] \\
\hline & NA & 25 & 25 & FFPE & qRT-PCR & 157 & Roehle et al. 2008 [32] \\
\hline \multirow{6}{*}{$\operatorname{miR}-221-3 p$} & \multirow{4}{*}{ Down GCB } & 11 & 18 & FFPE & qRT-PCR/array & 470 & Montes-Moreno et al. 2011 [45] \\
\hline & & 32 & 28 & FFPE & Array & 464 & Lawrie et al. 2009 [41] \\
\hline & & 16 & 18 & FF and FFPE & qRT-PCR & 3 & Lawrie et al. 2007 [33] \\
\hline & & 41 & 30 & $\mathrm{FF}$ & sequencing & miRNAome & Lim et al. 2015 [27] \\
\hline & \multirow{2}{*}{ NS } & 20 & 20 & Tissue & Array & 113 & Zhang et al. 2009 [43] \\
\hline & & 20 & 34 & FF and FFPE & qRT-PCR/array & 177 & Caramuta et al. 2013 [28] \\
\hline \multirow{7}{*}{ miR-222-3p } & \multirow{3}{*}{ Down GCB } & 11 & 18 & FFPE & qRT-PCR/array & 470 & Montes-Moreno et al. 2011 [45] \\
\hline & & 32 & 28 & FFPE & Array & 464 & Lawrie et al. 2009 [41] \\
\hline & & 41 & 30 & FF & sequencing & miRNAome & Lim et al. 2015 [27] \\
\hline & \multirow{4}{*}{ NS } & 25 & 25 & FFPE & qRT-PCR & 157 & Roehle et al. 2008 [32] \\
\hline & & 20 & 20 & Tissue & Array & 113 & Zhang et al. 2009 [43] \\
\hline & & 32 & 27 & FFPE & qRT-PCR/array & 377 & Iqbal et al. 2015 [38] \\
\hline & & 20 & 34 & FF and FFPE & qRT-PCR/array & 177 & Caramuta et al. 2013 [28] \\
\hline \multirow{4}{*}{ miR-146a-5p } & \multirow[t]{2}{*}{ Down GCB } & 20 & 34 & FF and FFPE & qRT-PCR/array & 177 & Caramuta et al. 2013 [28] \\
\hline & & 21 & 69 & FFPE & qRT-PCR & 2 & Zhong et al. 2012 [30] \\
\hline & \multirow{2}{*}{ NS } & 41 & 30 & FF & sequencing & miRNAome & Lim et al. 2015 [27] \\
\hline & & 20 & 20 & Tissue & Array & 113 & Zhang et al. 2009 [43] \\
\hline \multirow{6}{*}{ miR-146b-5p } & Down GCB & 32 & 28 & FFPE & Array & 464 & Lawrie et al. 2009 [41] \\
\hline & \multirow{5}{*}{ NS } & 32 & 27 & FFPE & gRT-PCR/array & 377 & Iqbal et al. 2015 [38] \\
\hline & & 41 & 30 & FF & sequencing & miRNAome & Lim et al. 2015 [27] \\
\hline & & 20 & 20 & Tissue & Array & 113 & Zhang et al. 2009 [43] \\
\hline & & 47 & 59 & FFPE & qRT-PCR & 2 & Wu et al. 2014 [21] \\
\hline & & 20 & 34 & FF and FFPE & qRT-PCR/array & 177 & Caramuta et al. 2013 [28] \\
\hline \multirow{6}{*}{$\operatorname{miR}-28-5 p$} & \multirow{4}{*}{ Up GCB } & 11 & 18 & FFPE & qRT-PCR/array & 470 & Montes-Moreno et al. 2011 [45] \\
\hline & & 32 & 27 & FFPE & qRT-PCR/array & 377 & Iqbal et al. 2015 [38] \\
\hline & & 41 & 30 & $\mathrm{FF}$ & sequencing & miRNAome & Lim et al. 2015 [27] \\
\hline & & 20 & 20 & Tissue & Array & 113 & Zhang et al. 2009 [43] \\
\hline & \multirow{2}{*}{ NS } & 20 & 34 & FF and FFPE & qRT-PCR/array & 177 & Caramuta et al. 2013 [28] \\
\hline & & 32 & 28 & FFPE & Array & 464 & Lawrie et al. 2009 [41] \\
\hline
\end{tabular}

GCB: Germinal center B-cell like; FF: fresh frozen; FFPE: formalin-fixed paraffin-embedded; NA: not available; Up: statistically significantly upregulated in the subtype of DLBCL patients; NS: no significant difference between patient subtypes; Down: significantly downregulated in the subtype of DLBCL patients. 
Table 3. miRNAs significantly associated with DLBCL prognosis in more than two studies.

\begin{tabular}{|c|c|c|c|c|c|c|}
\hline Significant miRNAs & Result & $n$ DLBCL & Sample Source & Method & n miRNAs & Reference \\
\hline \multirow{7}{*}{$\operatorname{miR}-222-3 p$} & Up: $\downarrow \mathrm{OS}$ & 176 & FFPE & qRT-PCR & 11 & Alencar et al. 2011 [48] \\
\hline & Up: $\downarrow$ PFS and OS & $36 / 240$ & FFPE & qRT-PCR/array & $470 / 9$ & Montes-Moreno et al. 2011 [45] \\
\hline & Up: $\downarrow$ OS and PFS & 106 & FFPE & gRT-PCR & 3 & Malumbres et al. 2009 [49] \\
\hline & \multirow{4}{*}{ NS } & 64 & FFPE & Array & 464 & Lawrie et al. 2009 [41] \\
\hline & & 92 & FF & sequencing & miRNAome & Lim et al. 2015 [27] \\
\hline & & 58 & Biopsie & qRT-PCR & 157 & Roehle et al. 2008 [32] \\
\hline & & 83 & FFPE & qRT-PCR/array & \pm 900 & Shepshelovich et al. 2015 [47] \\
\hline \multirow{11}{*}{$\operatorname{miR}-155-5 p$} & Up: $\downarrow$ survival & 118 & FF & gRT-PCR & 1 & Zhu et al. 2016 [46] \\
\hline & Up: $\downarrow$ OS & 79 & FFPE & qRT-PCR & 8 & Iqbal et al. 2015 [38] \\
\hline & Down: $\uparrow$ PFS & 90 & FFPE & qRT-PCR & 2 & Zhong et al. 2012 [30] \\
\hline & \multirow{8}{*}{ NS } & 176 & FFPE & qRT-PCR & 11 & Alencar et al. 2017 [48] \\
\hline & & 200 & FFPE & qRT-PCR & 3 & Go et al. 2015 [26] \\
\hline & & 35 & FF and FFPE & qRT-PCR & 3 & Lawrie et al. 2007 [33] \\
\hline & & 64 & FFPE & Array & 464 & Lawrie et al. 2009 [41] \\
\hline & & 92 & FF & sequencing & miRNAome & Lim et al. 2015 [27] \\
\hline & & 106 & FFPE & qRT-PCR & 3 & Malumbres et al. 2009 [49] \\
\hline & & 58 & Biopsie & qRT-PCR & 157 & Roehle et al. 2008 [32] \\
\hline & & 83 & FFPE & qRT-PCR/array & \pm 900 & Shepshelovich et al. 2015 [47] \\
\hline
\end{tabular}

FF: fresh frozen; FFPE: formalin-fixed paraffin-embedded; OS: overall survival; PFS: progression-free survival; EFS: event free survival; RFS: relapse free survival; Up: statistically significantly upregulated expression; NS: no significant association between expression and patient outcome; Down: significantly downregulated expression. $\downarrow$ : decreased; $\uparrow$ : increased.

Table 4. Coverage of DLBCL related pathway with miRNA predicted targets.

\begin{tabular}{|c|c|c|c|c|c|c|}
\hline Phenotype & $\begin{array}{c}\text { Pathway Name } \\
\text { Num. of Genes } \\
\text { Database }\end{array}$ & miRNA & $p$-value & FDR & n Target Genes & Coverage \\
\hline DLBCL Diagnosis & $\begin{array}{c}\text { MAPK signaling pathway (Homo sapiens) } \\
295 \text { genes } \\
\text { (KEGG) }\end{array}$ & $\begin{array}{l}\operatorname{miR}-155-5 p \\
\operatorname{miR}-21-5 p\end{array}$ & $3.42 \times 10^{-07}$ & 0.000293 & 73 & $24.7 \%$ \\
\hline $\begin{array}{l}\text { DLBCL } \\
\text { Subtype }\end{array}$ & $\begin{array}{c}\text { Signaling by Receptor Tyrosine Kinases } \\
422 \text { genes } \\
\text { (Reactome) }\end{array}$ & $\begin{array}{l}\operatorname{miR}-155-5 p \\
\operatorname{miR}-221-3 p\end{array}$ & $1.09 \times 10^{-07}$ & $6.25 \times 10^{-05}$ & 103 & $24.4 \%$ \\
\hline
\end{tabular}

$p$-value: absolute $p$-value; FDR: corrected $p$-value by "False Discovery Rate" method; pathway source: associated database. 


\section{Discussion}

In this systematic review, we have performed an in depth analysis of the current literature in relation to the potential role of miRNA expression in tumor biopsies as biomarker for diagnosis, subtype characterization, treatment response and prognosis in patients with DLBCL.

Regarding the suitability of miRNAs as diagnostic biomarkers in DLBCL, twenty one articles were identified, in which a total of four miRNAs (miR-155-5p [17,22,24,26,28,30,32-34], miR-21-5p [19,22,26,28,33,36], miR-150-5p [18,28,29,31,32]) and miR-146a/b-5p [21,22,27,30] were found to be significantly deregulated in DLBCL patients in more than two studies with concordant results. Among them, miR-155-5p and miR-21-5p presented the most consistent results, being found upregulated in DLBCL patients in most studies.

MiR-155-5p, was the most widely studied miRNA and was found to be upregulated in DLBCL patients in nine of the studies in which it was analyzed [17,22,24,26,28,30,32-34] while no significant association was found in the other two studies [27,29]. Among the two studies that did not find a significant association between mir-155-5p and DLBCL, one presented the smallest sample size with nineteen patients [29], and the other study followed stricter criteria for statistically significant associations [27]. In agreement with these results, previous studies have suggested that miR-155 could represent an onco-miR as its expression is activated in many tumors, i.e., prostate cancer, breast cancer, and other tumors, particularly those of the lymphoid tissue [50-52]. A possible explanation for its implication in DLBCL is that the validated targets of this miRNA include known hallmarks of DLBCL, such as SOSC or SHIP1 [53].

On the other hand, it is noteworthy that miR-21-5p, which was analyzed in eight independent studies, was significantly upregulated in DLBCL patients in six of them $[19,22,26,28,33,36]$, while no statistically significant association was found in the other two studies [27,32]. In agreement with this observation, miR-21 has been reported to be deregulated in most cancers, such as colorectal cancer, acting as an oncogene [54]. High levels of miR-21 have also been observed in B-NHLs. Overall, miR-21 is considered to be an onco-miR that acts through the inhibition of the expression of different phosphatases, such as PDCD4 (Programmed Cell Death 4) and PTEN (Phosphatase And Tensin Homolog), which control the activity of signaling pathways like AKT and MAPK [55].

Given that miR-155-5p and miR-21-5p seem the best candidates as putative diagnostic tools in patients with DLBCL, their functional implication was inferred by in silico analysis. This analysis showed that MAPK signaling pathway is over-represented among the combined predicted target genes of miR-155-5p and miR-21-5p (Table 4). Interestingly, the genes predicted to be targeted by miR-155-5p and miR-21-5p are in the first steps of the signaling cascade (CACN, RTK, IL1R or NIK). Aberrant expression of this pathway is a major and highly prevalent oncogenic event in many human cancers [56], including NHL [57], which could explain the role of these miRNAs in DLBCL. In this regard, miR-21-5p is also one of the most frequently upregulated circulating microRNAs previously described as a non-invasive diagnosis biomarker [9].

The utility of microRNAs for DLBCL classification has been analyzed by twenty studies. A total of five miRNAs (miR-155-5p [26-28,30,33,34,38,41,44], miR-221-3p [27,33,41,45], miR-222-3p [27,41,45], miR-146a/b-5p [28,41,43], and miR-28-5p [27,38,43,45]) were found to be deregulated in more than two studies. However, miR-222-3p, miR-146a/b-5p, and miR-28-5p showed contradictory results since they were not found to be significantly related to DLBCL classification in four $[28,32,38,43]$, five $[21,27,28,38,43]$ and two studies $[28,41]$, respectively. Some of the discrepancies might be due to the fact that subtype classification of the DLBCL patients was performed by GEP or IHC, which makes the studies less comparable due to the variable reproducibility of IHC stains and interpretations. The only miRNAs that showed more consistent results were miR-155-5p and miR-221-3p. MiR-155-5p was found to be upregulated in the $A B C$ subgroup in nine out of ten studies and only found to be not associated in a study which used IHC for classification and a more stringent requirement for differentially expressed miRNAs [32]. Mir-221-3p was found to be upregulated in the ABC subgroup in four of the six studies in which it was analyzed. 
Taking into account the two most consistent microRNAs related with DLBCL classification, miR-155-5p and miR-221-3p, in silico analysis showed that the Tyrosine Kinase pathway was over-represented among their predicted target genes (Table 4). Among the target genes of both microRNAs, we found PIK3R1 (p85), which is a negative regulator of the phosphatidylinositol 3-kinase (PI3K)-AKT pathway. Our data could indicate that overexpression of miR-155-5p and miR-221-3p in ABC subgroup repressed PIK3R1 (p85), the PIK regulatory subunit, activating the PI3K-AKT signaling pathway in this subtype. However, it should be noted that it would be difficult to classify different DLBCL subtypes simply based on those two miRNAs. Thus, additional molecular biomarkers would be needed for clinical application.

Focusing on miRNAs as predictive biomarkers of response to R-CHOP treatment, five studies were identified with no agreement in the miRNAs considered [18,23,24,30,42]. Among them, upregulation of miR-27-3p [18], miR-34a-5p [42] and miR-224-5p [23] were associated with chemosensitivity and miR-155-5p and miR-146-5p [30] were associated with chemoresistance (Table S3). Further studies are needed to confirm these preliminary results.

Finally, the implications of microRNAs in prognosis in DLBCL has been analyzed in nineteen studies including 50 significant miRNAs [18,20,21,23,25-27,30,32,33,41,42,45-49]. Among them, the expression of miR-222-3p [45,48,49], and miR-155-5p [30,38,46] were found to be associated with prognosis in more than two studies with concordant results. However, these miRNAs were analyzed in an equal or higher number of additional studies without finding any association with prognosis, which means that none of the analyzed miRNAs were established as a reliable marker of prognosis. It is noteworthy that most studies failed to report the specific treatment regimens, which would be of relevance in order to find prognostic biomarkers since prognosis is dependent on the specific treatment regimen.

Several limitations were faced while performing this systematic review. On the one hand, the studies performed usually considered a limited set of selected miRNAs, which limits the number of comparable results and centers the discussion on those miRNAs that are better known, leaving other miRNAs aside. It is necessary to perform large-scale studies with a wider array of miRNAs using techniques such as next-generation sequencing that allow the identification of new miRNAs. On the other hand, most studies analyzed in this revision relied on tissue-based miRNA detection using qRT-PCR. As a result, it is difficult to know whether the differentially expressed miRNAs directly result from DLBCL or from the cancer-associated microenvironment. Single-cell RNA sequencing methods, developed in recent years, may provide a better approach to achieve this goal in future studies. Further, the included studies present great heterogeneity in sample sources, types of controls used or methodology for expression analysis. This methodological variability could be a source of differences in results among studies. Since the effect of such differences is difficult to determine in the context of a review, it would be of great relevance to reach a consensus and standardize the methodology of study used for future studies in order to facilitate reproducibility and comparisons among studies.

In addition, there is variability in the cut-off value for statistical significance among studies, which we considered to be a potential source of heterogeneity. Finally, there is a tendency to only publish statistically significant results, which leads to bias. All of these limitations in the published literature may be contributing to the lack of consistency in many of the results, which makes it difficult to draw final conclusions about the role of some of the miRNAs analyzed as biomarkers in DLBCL.

\section{Materials and Methods}

\subsection{Systematic Review}

\subsubsection{Search Strategy}

A systematic search with the terms "(('Non-coding RNA') OR ('miRNA' OR 'microRNA' OR 'miR') OR ('exosome') OR ('extracellular vesicle') OR ('secretome')) AND ('Diffuse large B cell lymphoma' 
OR 'DLBCL')", following the same strategy used in our previously published review on circulating miRNAs [9] was performed using the PubMed database (https:/ / www.ncbi.nlm.nih.gov/pubmed/), including articles published until December 2017.

\subsubsection{Inclusion and exclusion criteria}

Independent original studies that evaluated the expression of miRNAs in DLBCL tumor tissue as diagnosis, subtype, prediction of treatment response or prognosis biomarkers in human patient populations were included. Exclusion criteria encompassed: articles not including original data (reviews, meta-analyses, letters, and comments), case reports, abstracts, articles not published in English, studies that did not include miRNA data on human populations, and studies on diseases other than DLBCL. After full text revision, articles that included other diseases, analyzed circulating miRNAs, were focused on non-primary DLBCL, did not assess the role of miRNAs in diagnosis, subtype, treatment response, or prognosis, or did not analyze miRNA expression, were excluded. References within the identified studies were reviewed to identify additional matches. Study selection was performed by two researchers independently (AL and BS) and disagreements were resolved by consensus.

\subsubsection{Data Extraction}

The following information was extracted from each study: publication year, type of tissue sample analyzed, characteristics of the study population, methodology, number of miRNAs studied, and the list of differentially expressed miRNAs provided. Only the miRNAs that were reported as statistically significant in more than two studies with consistent results were selected.

\subsection{Data Analysis}

\subsubsection{Target Genes Selection}

In order to predict the putative target genes for the miRNAs identified in the systematic search, miRWalk 2.0 database (http:/ / zmf.umm.uni-heidelberg.de/apps/zmf/mirwalk2/) [58] was used. Only those genes predicted by 6 or more of the 12 available prediction algorithms available at miRWalk 2.0 were taken into account.

\subsubsection{Pathway Enrichment Analysis}

In order to analyze pathways enrichment within the lists of predicted target genes, the over-representation analysis module of the ConsensusPathDB web tool (CPdB) (http:// consensuspathdb.org/) was used [59]. Within this tool, KEGG (https:/ /www.genome.jp/kegg/) [60], Reactome (https://reactome.org/PathwayBrowser/) [61] and BioCarta (http:/ /cgap.nci.nih.gov/ Pathways/BioCarta_Pathways) databases were interrogated, assuming a conservative $p$-value cutoff of 0.0001 .

\section{Conclusions}

In this systematic review, we have identified that the expression of miR-155-5p and mir-21-5p shows the potential for utility in diagnosis, while mir-155-5p and mir-21-5p could be of use for DLBCL classification. Nevertheless, other associations between miRNA expression and DLBCL phenotypes showed contradictory results. We can conclude that this is a very promising field of study, which could also help to identify novel therapeutic targets and strategies to guide treatment choice. In order to exploit the potential of this field, it would be of particular interest to perform large-scale studies with large sample sizes and a wider array of miRNAs, including unknown miRNAs. 
Supplementary Materials: The following are available online at http:/ / www.mdpi.com/2072-6694/11/2/144/s1, Table S1: Differentially expressed microRNAs in DLBCL patients compared with healthy control individuals, Table S2: Differentially expressed microRNAs in DLBCL subtypes, Table S3: Differentially expressed microRNAs as prediction to response to R-CHOP therapy, Table S4: Differentially expressed microRNAs as prognosis biomarkers, Table S5: Pathways significantly enriched among hsa-miR-155-5p and hsa-miR-21-5p (DLBCL diagnosis) target genes predicted by 6 or more databases, Table S6: Pathways significantly enriched among hsa-miR-155-5p, hsa-miR-221-3p (DLBCL subtype) target genes predicted by 6 or more databases.

Author Contributions: E.L.-L. and A.G.-O. contributed to the conception and design of the study. A.L.-E., B.S.-Z. and M.L.-S., acquired and analyzed the data. A.L.-E., B.S.-Z., E.L.-L. and A.G.-O. interpreted the results and drafted the article. E.L.-L and A.G.-O. acquired and administrated the funding. All authors have read, reviewed critically and approved the final manuscript.

Funding: This study was funded by the Basque Government (IT989-16), and Bioef-EiTB maratoia (BIO15/CA/022). The funding source did not have any role in the study design, collection, analysis and interpretation of data, writing of the report, or decision to submit the article for publication.

Conflicts of Interest: The authors declare no conflict of interest.

\section{References}

1. Swerdlow, S.H.; Campo, E.; Pileri, S.A.; Harris, N.L.; Stein, H.; Siebert, R.; Advani, R.; Ghielmini, M.; Salles, G.A.; Zelenetz, A.D.; et al. The 2016 revision of the World Health Organization classification of lymphoid neoplasms. Blood 2016, 127, 2375-2390. [CrossRef] [PubMed]

2. Zhang, J.; Grubor, V.; Love, C.L.; Banerjee, A.; Richards, K.L.; Mieczkowski, P.A.; Dunphy, C.; Choi, W.; $\mathrm{Au}$, W.Y.; Srivastava, G.; et al. Genetic heterogeneity of diffuse large B-cell lymphoma. Proc. Natl. Acad. Sci. USA 2013, 110, 1398-1403. [CrossRef] [PubMed]

3. Coiffier, B.; Thieblemont, C.; Van Den Neste, E.; Lepeu, G.; Plantier, I.; Castaigne, S.; Lefort, S.; Marit, G.; Macro, M.; Sebban, C.; et al. Long-term outcome of patients in the LNH-98.5 trial, the first randomized study comparing rituximab-CHOP to standard CHOP chemotherapy in DLBCL patients: A study by the Groupe d'Etudes des Lymphomes de l'Adulte. Blood 2010, 116, 2040-2045. [CrossRef] [PubMed]

4. Raut, L.S.; Chakrabarti, P.P. Management of relapsed-refractory diffuse large B cell lymphoma. South Asian J. Cancer 2014, 3, 66-70. [CrossRef] [PubMed]

5. The International Non-Hodgkin's Lymphoma Prognostic Factors Project. A predictive model for aggressive non-Hodgkin's lymphoma. N. Engl. J. Med. 1993, 329, 987-994. [CrossRef] [PubMed]

6. Sehn, L.H.; Berry, B.; Chhanabhai, M.; Fitzgerald, C.; Gill, K.; Hoskins, P.; Klasa, R.; Savage, K.J.; Shenkier, T.; Sutherland, J.; et al. The revised International Prognostic Index (R-IPI) is a better predictor of outcome than the standard IPI for patients with diffuse large B-cell lymphoma treated with R-CHOP. Blood 2007, 109, 1857-1861. [CrossRef] [PubMed]

7. Alizadeh, A.A.; Eisen, M.B.; Davis, R.E.; Ma, C.; Lossos, I.S.; Rosenwald, A.; Boldrick, J.C.; Sabet, H.; Tran, T.; $\mathrm{Yu}, \mathrm{X}$.; et al. Distinct types of diffuse large B-cell lymphoma identified by gene expression profiling. Nature 2000, 403, 503-511. [CrossRef] [PubMed]

8. Rosenwald, A.; Wright, G.; Chan, W.C.; Connors, J.M.; Campo, E.; Fisher, R.I.; Gascoyne, R.D.; Muller-Hermelink, H.K.; Smeland, E.B.; Giltnane, J.M.; et al. The Use of Molecular Profiling to Predict Survival after Chemotherapy for Diffuse Large-B-Cell Lymphoma. N. Engl. J. Med. 2002, 346, 1937-1947. [CrossRef]

9. Lopez-Santillan, M.; Larrabeiti-Etxebarria, A.; Arzuaga-Mendez, J.; Lopez-Lopez, E.; Garcia-Orad, A. Circulating miRNAs as biomarkers in diffuse large B-cell lymphoma: A systematic review. Oncotarget 2018, 9, 22850-22861. [CrossRef]

10. Gutierrez-Camino, A.; Umerez, M.; Santos, B.; Martin-Guerrero, I.; García de Andoin, N.; Sastre, A.; Navajas, A.; Astigarraga, I.; Garcia-Orad, A. Pharmacoepigenetics in childhood acute lymphoblastic leukemia: Involvement of miRNA polymorphisms in hepatotoxicity. Epigenomics 2018, 10, 409-417. [CrossRef]

11. Kozomara, A.; Griffiths-Jones, S. miRBase: Annotating high confidence microRNAs using deep sequencing data. Nucleic Acids Res. 2014, 42, D68-D73. [CrossRef] [PubMed]

12. Hanahan, D.; Weinberg, R.A. Hallmarks of Cancer: The Next Generation. Cell 2011, 144, 646-674. [CrossRef] [PubMed] 
13. Hahne, J.C.; Valeri, N. Non-Coding RNAs and Resistance to Anticancer Drugs in Gastrointestinal Tumors. Front. Oncol. 2018, 8, 226. [CrossRef] [PubMed]

14. Bica-Pop, C.; Cojocneanu-Petric, R.; Magdo, L.; Raduly, L.; Gulei, D.; Berindan-Neagoe, I. Overview upon miR-21 in lung cancer: Focus on NSCLC. Cell. Mol. Life Sci. 2018, 75, 3539-3551. [CrossRef] [PubMed]

15. Cancer Genome Atlas Research Network; Linehan, W.M.; Spellman, P.T.; Ricketts, C.J.; Creighton, C.J.; Fei, S.S.; Davis, C.; Wheeler, D.A.; Murray, B.A.; Schmidt, L.; et al. Comprehensive Molecular Characterization of Papillary Renal-Cell Carcinoma. N. Engl. J. Med. 2015, 374, 135-145. [PubMed]

16. Zhang, X.-L.; Pan, S.-H.; Yan, J.-J.; Xu, G. The prognostic value of microRNA-183 in human cancers: A meta-analysis. Medicine 2018, 97, e11213. [CrossRef] [PubMed]

17. Li, X.-D.; Li, X.-M.; Gu, J.-W.; Sun, X.-C. MiR-155 regulates lymphoma cell proliferation and apoptosis through targeting SOCS3/JAK-STAT3 signaling pathway. Eur. Rev. Med. Pharmacol. Sci. 2017, 21, 5153-5159. [PubMed]

18. Jia, Y.J.; Liu, Z.B.; Wang, W.G.; Sun, C.B.; Wei, P.; Yang, Y.L.; You, M.J.; Yu, B.H.; Li, X.Q.; Zhou, X.Y. HDAC6 regulates microRNA-27b that suppresses proliferation, promotes apoptosis and target MET in diffuse large B-cell lymphoma. Leukemia 2017, 32, 703-711. [CrossRef]

19. Liu, K.; Du, J.; Ruan, L. MicroRNA-21 regulates the viability and apoptosis of diffuse large B-cell lymphoma cells by upregulating B cell lymphoma-2. Exp. Ther. Med. 2017, 14, 4489-4496. [CrossRef]

20. Wang, W.; Yang, C.; Han, X.; Wang, R.; Huang, Y.; Zi, Y.; Li, J. MicroRNA-23a expression in paraffin-embedded specimen correlates with overall survival of diffuse large B-cell lymphoma. Med. Oncol. 2014, 31, 919. [CrossRef]

21. Wu, P.Y.; Zhang, X.D.; Zhu, J.; Guo, X.Y.; Wang, J.F. Low expression of microRNA-146b-5p and microRNA-320d predicts poor outcome of large B-cell lymphoma treated with cyclophosphamide, doxorubicin, vincristine, and prednisone. Hum. Pathol. 2014, 45, 1664-1673. [CrossRef] [PubMed]

22. Tamaddon, G.; Geramizadeh, B.; Karimi, M.H.; Mowla, S.J.; Abroun, S. miR-4284 and miR-4484 as Putative Biomarkers for Diffuse Large B-Cell Lymphoma. Iran. J. Med. Sci. 2016, 41, 334-339. [PubMed]

23. Ni, H.; Wang, X.; Liu, H.; Tian, F.; Song, G. Low expression of miRNA-224 predicts poor clinical outcome in diffuse large B-cell lymphoma treated with R-CHOP. Biomarkers 2015, 20, 253-257. [CrossRef] [PubMed]

24. Huskova, H.; Korecka, K.; Karban, J.; Vargova, J.; Vargova, K.; Dusilkova, N.; Trneny, M.; Stopka, T. Oncogenic microRNA-155 and its target PU.1: An integrative gene expression study in six of the most prevalent lymphomas. Int. J. Hematol. 2015, 102, 441-450. [CrossRef] [PubMed]

25. Troppan, K.; Wenzl, K.; Pichler, M.; Pursche, B.; Schwarzenbacher, D.; Feichtinger, J.; Thallinger, G.G.; Beham-Schmid, C.; Neumeister, P.; Deutsch, A. miR-199a and miR-497 Are Associated with Better Overall Survival due to Increased Chemosensitivity in Diffuse Large B-Cell Lymphoma Patients. Int. J. Mol. Sci. 2015, 16, 18077-18095. [CrossRef] [PubMed]

26. Go, H.; Jang, J.-Y.; Kim, P.-J.; Kim, Y.-G.; Nam, S.J.; Paik, J.H.; Kim, T.M.; Heo, D.S.; Kim, C.-W.; Jeon, Y.K. MicroRNA-21 plays an oncogenic role by targeting FOXO1 and activating the PI3K/AKT pathway in diffuse large B-cell lymphoma. Oncotarget 2015, 6, 15035-15049. [CrossRef] [PubMed]

27. Lim, E.L.; Trinh, D.L.; Scott, D.W.; Chu, A.; Krzywinski, M.; Zhao, Y.; Robertson, A.G.; Mungall, A.J.; Schein, J.; Boyle, M.; et al. Comprehensive miRNA sequence analysis reveals survival differences in diffuse large B-cell lymphoma patients. Genome Biol. 2015, 16, 18. [CrossRef]

28. Caramuta, S.; Lee, L.; Ozata, D.M.; Akçakaya, P.; Georgii-Hemming, P.; Xie, H.; Amini, R.-M.; Lawrie, C.H.; Enblad, G.; Larsson, C.; et al. Role of microRNAs and microRNA machinery in the pathogenesis of diffuse large B-cell lymphoma. Blood Cancer J. 2013, 3, e152. [CrossRef]

29. Handal, B.; Enlow, R.; Lara, D.; Bailey, M.; Vega, F.; Hu, P.; Lennon, A. Investigating the Expression of Oncogenic and Tumor Suppressive MicroRNA in DLBCL. J. Assoc. Genet. Technol. 2013, 39, 14-20.

30. Zhong, H.; Xu, L.; Zhong, J.-H.; Xiao, F.; Liu, Q.; Huang, H.-H.; Chen, F.-Y. Clinical and prognostic significance of miR-155 and miR-146a expression levels in formalin-fixed/paraffin-embedded tissue of patients with diffuse large B-cell lymphoma. Exp. Ther. Med. 2012, 3, 763-770. [CrossRef]

31. Fassina, A.; Marino, F.; Siri, M.; Zambello, R.; Ventura, L.; Fassan, M.; Simonato, F.; Cappellesso, R. The miR-17-92 microRNA cluster: A novel diagnostic tool in large B-cell malignancies. Lab. Investig. 2012, 92, 1574-1582. [CrossRef] [PubMed] 
32. Roehle, A.; Hoefig, K.P.; Repsilber, D.; Thorns, C.; Ziepert, M.; Wesche, K.O.; Thiere, M.; Loeffler, M.; Klapper, W.; Pfreundschuh, M.; et al. MicroRNA signatures characterize diffuse large B-cell lymphomas and follicular lymphomas. Br. J. Haematol. 2008, 142, 732-744. [CrossRef] [PubMed]

33. Lawrie, C.H.; Soneji, S.; Marafioti, T.; Cooper, C.D.O.; Palazzo, S.; Paterson, J.C.; Cattan, H.; Enver, T.; Mager, R.; Boultwood, J.; et al. Microrna expression distinguishes between germinal center B cell-like and activated B cell-like subtypes of diffuse large B cell lymphoma. Int. J. Cancer 2007, 121, 1156-1161. [CrossRef] [PubMed]

34. Eis, P.S.; Tam, W.; Sun, L.; Chadburn, A.; Li, Z.; Gomez, M.F.; Lund, E.; Dahlberg, J.E. Accumulation of miR-155 and BIC RNA in human B cell lymphomas. Proc. Natl. Acad. Sci. USA 2005, 102, 3627-3632. [CrossRef] [PubMed]

35. Fan, Q.; Meng, X.; Liang, H.; Zhang, H.; Liu, X.; Li, L.; Li, W.; Sun, W.; Zhang, H.; Zen, K.; et al. miR-10a inhibits cell proliferation and promotes cell apoptosis by targeting BCL6 in diffuse large B-cell lymphoma. Protein Cell 2016, 7, 899-912. [CrossRef] [PubMed]

36. Song, J.; Shao, Q.; Li, C.; Liu, H.; Li, J.; Wang, Y.; Song, W.; Li, L.; Wang, G.; Shao, Z.; et al. Effects of microRNA-21 on apoptosis by regulating the expression of PTEN in diffuse large B-cell lymphoma. Medicine 2017, 96, e7952. [CrossRef] [PubMed]

37. Berglund, M.; Hedström, G.; Amini, R.M.; Enblad, G.; Thunberg, U. High expression of microRNA-200c predicts poor clinical outcome in diffuse large B-cell lymphoma. Oncol. Rep. 2012, 29, 720-724. [CrossRef]

38. Iqbal, J.; Shen, Y.; Huang, X.; Liu, Y.; Wake, L.; Liu, C.; Deffenbacher, K.; Lachel, C.M.; Wang, C.; Rohr, J.; et al. Global microRNA expression profiling uncovers molecular markers for classification and prognosis in aggressive B-cell lymphoma. Blood 2015, 125, 1137-1145. [CrossRef]

39. Kim, S.-W.; Ramasamy, K.; Bouamar, H.; Lin, A.-P.; Jiang, D.; Aguiar, R.C.T. MicroRNAs miR-125a and miR-125b constitutively activate the NF- $\mathrm{BB}$ pathway by targeting the tumor necrosis factor alpha-induced protein 3 (TNFAIP3, A20). Proc. Natl. Acad. Sci. USA 2012, 109, 7865-7870. [CrossRef]

40. Nie, K.; Zhang, T.; Allawi, H.; Gomez, M.; Liu, Y.; Chadburn, A.; Wang, Y.L.; Knowles, D.M.; Tam, W. Epigenetic down-regulation of the tumor suppressor gene PRDM1/Blimp-1 in diffuse large B cell lymphomas: A potential role of the microRNA let-7. Am. J. Pathol. 2010, 177, 1470-1479. [CrossRef]

41. Lawrie, C.H.; Chi, J.; Taylor, S.; Tramonti, D.; Ballabio, E.; Palazzo, S.; Saunders, N.J.; Pezzella, F.; Boultwood, J.; Wainscoat, J.S.; et al. Expression of microRNAs in diffuse large B cell lymphoma is associated with immunophenotype, survival and transformation from follicular lymphoma. J. Cell. Mol. Med. 2009, 13, 1248-1260. [CrossRef] [PubMed]

42. Marques, S.C.; Ranjbar, B.; Laursen, M.B.; Falgreen, S.; Bilgrau, A.E.; Bødker, J.S.; Jørgensen, L.K.; Primo, M.N.; Schmitz, A.; Ettrup, M.S.; et al. High miR-34a expression improves response to doxorubicin in diffuse large B-cell lymphoma. Exp. Hematol. 2016, 44, 238-246.e2. [CrossRef] [PubMed]

43. Zhang, J.; Jima, D.D.; Jacobs, C.; Fischer, R.; Gottwein, E.; Huang, G.; Lugar, P.L.; Lagoo, A.S.; Rizzieri, D.A.; Friedman, D.R.; et al. Patterns of microRNA expression characterize stages of human B-cell differentiation. Blood 2009, 113, 4586-4594. [CrossRef] [PubMed]

44. Huang, X.; Shen, Y.; Liu, M.; Bi, C.; Jiang, C.; Iqbal, J.; McKeithan, T.W.; Chan, W.C.; Ding, S.-J.; Fu, K. Quantitative proteomics reveals that miR-155 regulates the PI3K-AKT pathway in diffuse large B-cell lymphoma. Am. J. Pathol. 2012, 181, 26-33. [CrossRef] [PubMed]

45. Montes-Moreno, S.; Martinez, N.; Sanchez-Espiridión, B.; Díaz Uriarte, R.; Rodriguez, M.E.; Saez, A.; Montalbán, C.; Gomez, G.; Pisano, D.G.; García, J.F.; et al. miRNA expression in diffuse large B-cell lymphoma treated with chemoimmunotherapy. Blood 2011, 118, 1034. [CrossRef] [PubMed]

46. Zhu, F.; Zeng, L.; Tang, N.; Tang, Y.; Zhou, B.; Li, F.; Wu, W.; Zeng, X.; Peng, S. MicroRNA-155 Downregulation Promotes Cell Cycle Arrest and Apoptosis in Diffuse Large B-Cell Lymphoma. Oncol. Res. Featur. Preclin. Clin. Cancer Ther. 2016, 24, 415-427. [CrossRef]

47. Shepshelovich, D.; Ram, R.; Uziel, O.; Kushnir, M.; Lithwick-Yanai, G.; Hoshen, M.; Feinmesser, M.; Bairey, O.; Lahav, M. MicroRNA signature is indicative of long term prognosis in diffuse large B-cell lymphoma. Leuk. Res. 2015, 39, 632-637. [CrossRef]

48. Alencar, A.J.; Malumbres, R.; Kozloski, G.A.; Advani, R.; Talreja, N.; Chinichian, S.; Briones, J.; Natkunam, Y.; Sehn, L.H.; Gascoyne, R.D.; et al. MicroRNAs Are Independent Predictors of Outcome in Diffuse Large B-Cell Lymphoma Patients Treated with R-CHOP. Clin. Cancer Res. 2011, 17, 4125-4135. [CrossRef] 
49. Malumbres, R.; Sarosiek, K.A.; Cubedo, E.; Ruiz, J.W.; Jiang, X.; Gascoyne, R.D.; Tibshirani, R.; Lossos, I.S. Differentiation stage-specific expression of microRNAs in B lymphocytes and diffuse large B-cell lymphomas. Blood 2009, 113, 3754-3764. [CrossRef]

50. Testa, U.; Pelosi, E.; Castelli, G.; Labbaye, C. miR-146 and miR-155: Two Key Modulators of Immune Response and Tumor Development. Noncoding RNA 2017, 3, 22. [CrossRef]

51. McInnes, N.; Sadlon, T.J.; Brown, C.Y.; Pederson, S.; Beyer, M.; Schultze, J.L.; McColl, S.; Goodall, G.J.; Barry, S.C. FOXP3 and FOXP3-regulated microRNAs suppress SATB1 in breast cancer cells. Oncogene 2011, 31, 1045-1054. [CrossRef] [PubMed]

52. Guo, T.; Wang, X.-X.; Fu, H.; Tang, Y.-C.; Meng, B.-Q.; Chen, C.-H. Early diagnostic role of PSA combined miR-155 detection in prostate cancer. Eur. Rev. Med. Pharmacol. Sci. 2018, 22, 1615-1621. [PubMed]

53. Pedersen, I.M.; Otero, D.; Kao, E.; Miletic, A.V.; Hother, C.; Ralfkiaer, E.; Rickert, R.C.; Gronbaek, K.; David, M. Onco-miR-155 targets SHIP1 to promote TNFalpha-dependent growth of B cell lymphomas. EMBO Mol. Med. 2009, 1, 288-295. [CrossRef] [PubMed]

54. Peng, Q.; Zhang, X.; Min, M.; Zou, L.; Shen, P.; Zhu, Y. The clinical role of microRNA-21 as a promising biomarker in the diagnosis and prognosis of colorectal cancer: A systematic review and meta-analysis. Oncotarget 2017, 8, 44893-44909. [CrossRef] [PubMed]

55. Musilova, K.; Mraz, M. MicroRNAs in B-cell lymphomas: How a complex biology gets more complex. Leukemia 2014, 29, 1004-1017. [CrossRef] [PubMed]

56. Stramucci, L.; Pranteda, A.; Bossi, G. Insights of Crosstalk between p53 Protein and the MKK3/MKK6/p38 MAPK Signaling Pathway in Cancer. Cancers 2018, 10, 131. [CrossRef] [PubMed]

57. Anders, P.; Bhende, P.M.; Foote, M.; Dittmer, D.P.; Park, S.I.; Damania, B. Dual inhibition of phosphatidylinositol 3-kinase/mammalian target of rapamycin and mitogen activated protein kinase pathways in non-Hodgkin lymphoma. Leuk. Lymphoma 2015, 56, 263-266. [CrossRef]

58. Dweep, H.; Gretz, N. miRWalk2.0: A comprehensive atlas of microRNA-target interactions. Nat. Methods 2015, 12, 697. [CrossRef]

59. Kamburov, A.; Stelzl, U.; Lehrach, H.; Herwig, R. The ConsensusPathDB interaction database: 2013 update. Nucleic Acids Res. 2013, 41, D793-D800. [CrossRef]

60. Kanehisa, M.; Sato, Y.; Kawashima, M.; Furumichi, M.; Tanabe, M. KEGG as a reference resource for gene and protein annotation. Nucleic Acids Res. 2016, 44, D457-D462. [CrossRef]

61. Fabregat, A.; Sidiropoulos, K.; Garapati, P.; Gillespie, M.; Hausmann, K.; Haw, R.; Jassal, B.; Jupe, S.; Korninger, F.; McKay, S.; et al. The Reactome pathway Knowledgebase. Nucleic Acids Res. 2016, 44, D481-D487. [CrossRef] 